\title{
Impacts of rice varieties and management on yield-scaled greenhouse gas emissions from rice fields in China: A meta-analysis
}

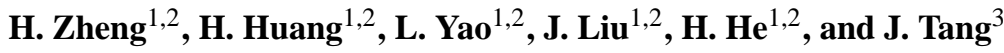 \\ ${ }^{1}$ College of Agronomy, Hunan Agricultural University, Changsha 410128, China \\ ${ }^{2}$ Key Laboratory of Multi-cropping Cultivation and Farming System, Ministry of Agriculture of PRC, \\ Changsha 410128, China \\ ${ }^{3}$ The Ecosystems Center, Marine Biological Laboratory, Woods Hole, MA 02543, USA \\ Correspondence to: H. Huang (hh863@126.com) and J. Tang (jtang@mbl.edu)
}

Received: 12 November 2013 - Published in Biogeosciences Discuss.: 4 December 2013

Revised: 28 March 2014 - Accepted: 31 May 2014 - Published: 10 July 2014

\begin{abstract}
Increasing numbers of studies have suggested that a comprehensive assessment of the impacts of cropping practices on greenhouse gas (GHG) emissions per unit yield (yield-scaled), rather than by land area (areascaled), is needed to inform trade-off decisions to increase yields and reduce GHG emissions. We conducted a meta-analysis to quantify impacts of rice varieties on the global warming potential (GWP) of GHG emissions at the yield scale in China. Our results showed that significantly higher yield-scaled GWP occurred with indica rice varieties $\left(1101.72 \mathrm{~kg} \mathrm{CO}_{2}\right.$ equiv. $\mathrm{Mg}^{-1}$ ) than japonica rice varieties $\left(711.38 \mathrm{~kg} \mathrm{CO}_{2}\right.$ equiv. $\left.\mathrm{Mg}^{-1}\right)$. Lower yield-scaled GHG emissions occurred within 120 130 days of growth duration after transplanting (GDAT; $613.66 \mathrm{~kg} \mathrm{CO}_{2}$ equiv. $\mathrm{Mg}^{-1}$ ), followed by $90-100$ days of GDAT (749.72 $\mathrm{kg} \mathrm{CO}_{2}$ equiv. $\mathrm{Mg}^{-1}$ ), 100-110 days of GDAT (794.29 $\mathrm{kg} \mathrm{CO}_{2}$ equiv. $\mathrm{Mg}^{-1}$ ), and 70-80 days of GDAT ( $800.85 \mathrm{~kg} \mathrm{CO}_{2}$ equiv. $\mathrm{Mg}^{-1}$ ). The fertilizer rate of $150-200 \mathrm{~kg} \mathrm{~N} \mathrm{ha}^{-1}$ resulted in the lowest yield-scaled GWP. Consequently, appropriate cultivar choice and pairs were of vital importance in the rice cropping system. A further life cycle assessment of GHG emissions among rice varieties at the yield scale is urgently needed to develop win-win policies for rice production to achieve higher yield with lower emissions.
\end{abstract}

\section{Introduction}

Agriculture is estimated to account for $10-12 \%$ of anthropogenic emissions of greenhouse gases (GHG) worldwide, including $60 \%$ of global nitrous oxide $\left(\mathrm{N}_{2} \mathrm{O}\right)$ emissions and $50 \%$ of methane $\left(\mathrm{CH}_{4}\right)$ emissions (Smith et al., 2007). Rice paddies are considered one of the most important sources of atmospheric $\mathrm{CH}_{4}$ (IPCC, 1992), but they also emit $\mathrm{N}_{2} \mathrm{O}$ and the intensity of emissions is related to the nitrogen $(\mathrm{N})$ fertilizer application rate (Zou et al., 2007). China ranks first in the world in annual rice production (FAOSTAT, 2011). To ensure food security for its increasing population, Chinese rice production needs to increase by $20 \%$ by 2030 (Peng et al., 2009). The increasing demand for rice in the future has raised tremendous concerns about increasing GHG emissions (van Beek et al., 2010; Zhang et al., 2011; van Groenigen et al., 2012). Information on trade-off between rice yield increases and GHG emission reductions is urgently needed to aid cropping technique innovation and policy selection. Recently, increasing numbers of studies have suggested that a comprehensive assessment of the impacts of cropping practices on GHG emissions per unit yield (yield-scaled), rather than by land area (area-scaled), will be beneficial for maintaining high yields, while reducing GHG emissions for decisionmaking (van Groenigen et al., 2010; Linquist et al., 2012a). Area-based GHG emission information alone is not sufficient to assess the future trend of emissions under the context of increasing yields and the changing climate. 
Rice paddies could contribute to more than $80 \%$ of $\mathrm{CH}_{4}$ and $\mathrm{N}_{2} \mathrm{O}$ emissions driven by microbial activities (Yu et al., 1997), and rice varieties could affect $\mathrm{N}_{2} \mathrm{O}$ and $\mathrm{CH}_{4}$ emissions in paddy fields (Fu et al., 2009; Baruah et al., 2010). While decomposition and methanogenesis processes in soil and rice rooting zones produce GHGs via ebullition and molecular diffusion, the lacunae transport through aerenchyma in rice plants is considered the most important in emitting $\mathrm{CH}_{4}$ to the atmosphere (Wang et al., 1995). Rice plants develop an intercellular gas space system, the aerenchyma, which provides roots with oxygen $\left(\mathrm{O}_{2}\right)$ submerged in inundated soils. This gas space system also enables the transport of other gases, including $\mathrm{CH}_{4}, \mathrm{~N}_{2} \mathrm{O}$ and carbon dioxide $\left(\mathrm{CO}_{2}\right)$ from the soil/sediment to the atmosphere. Consequently, the variation among rice varieties with different growth and developmental progresses could result in differences in total GHG emissions among rice varieties.

China grows a large number of rice varieties, especially hybrid rice varieties. For example, up to 2013, 101 cultivars were approved as super-high-yielding rice by the national Ministry of Agriculture in China. These cultivars can produce $15-20 \%$ higher yields than traditional hybrids under traditional cultivation (Wang et al., 2005). Although higher yields can often be obtained through genetic improvements, it is not clear how the aerenchyma system varies among these cultivars and how the gas transfer capacity in the root-shoot transition zone influences GHG emissions associated with the yield increase (Butterbach-Bahl et al. 1997). Thus, the question remains whether the yield increase is large enough to offset the corresponding increases in $\mathrm{N}_{2} \mathrm{O}$ and $\mathrm{CH}_{4}$ emissions to achieve an overall lower yield-scaled global warming potential (GWP). In this study, we limit GWP to $\mathrm{N}_{2} \mathrm{O}$ and $\mathrm{CH}_{4}$ emissions and do not include $\mathrm{CO}_{2}$, as $\mathrm{CO}_{2}$ emissions and uptake have been widely studied (e.g., Zhang et al., 2010; Shang et al., 2011).

The different growing length of cultivars affects GHG emissions. Khush et al. (1995) reported that the optimum growth duration for maximum rice yield in the tropics is 120 days from seed germination to seed production. To facilitate adaptation to multiple cropping systems, varieties with growth durations of 100-130 days are required. In transplanted rice, varieties with shorter growth durations usually produce lower yields with conventional spacing because they do not produce sufficient vegetative growth to achieve maximum yields (Yoshida, 1976). However, shorter growth duration is not necessarily associated with smaller GHG emissions during this period. To gain a win-win situation that produces high yields with lower GHG emissions, rice cultivars with the optimal length of the growth duration after transplanting (GDAT) should be carefully selected.

The application of $\mathrm{N}$ fertilizer is one of the primary methods for enhancing rice production, but field measurements have shown contradictory results for $\mathrm{CH}_{4}$ emissions caused by $\mathrm{N}$ fertilization application. Some studies reported that $\mathrm{N}$ fertilization significantly stimulated $\mathrm{CH}_{4}$ emissions (Lindau et al., 1991; Singh et al., 1996), but other studies found significant reductions in $\mathrm{CH}_{4}$ emissions with $\mathrm{N}$ fertilizer application (Zou et al., 2005; Xie et al., 2010). Based on existing data, determining an optimal rate of $\mathrm{N}$ fertilization for higher yield rice varieties while reducing $\mathrm{CH}_{4}$ emissions is difficult. In contrast, $\mathrm{N}$ fertilizer has been approved to increase $\mathrm{N}_{2} \mathrm{O}$ emissions (Kumar et al., 2000; Zou et al., 2005). N fertilizer promotes both nitrification and denitrification processes that produce $\mathrm{N}_{2} \mathrm{O}$ emissions.

During the past decades, many studies have examined the effects of rice varieties on rice yields (e.g., Ma et al., 2010; Fu et al., 2012) or GHG emissions (e.g., Ma et al., 2010; Mu et al., 2011; Fu et al., 2012) in China. These studies provide good opportunities to quantify the impacts of rice varieties on GHG emissions at the yield scale through meta-analyses. Here, we conducted a meta-analysis to quantitatively assess impacts of rice varieties, growth duration after transplanting (GDAT), and soil fertility management practices on yieldscaled GHG emissions. We aim to provide a new perspective to select rice varieties based on yield-scald GHG emissions within certain growth duration after transplanting to achieve higher yields with lower GHG emissions.

\section{Materials and methods}

\subsection{Data selection}

In this meta-analysis, we conducted a literature survey of peer-reviewed papers related to rice yield and $\mathrm{CH}_{4}$ and $\mathrm{N}_{2} \mathrm{O}$ emissions from Chinese rice fields published before June 2013. $\mathrm{CO}_{2}$ emissions and uptake are not included in this study. To include as many studies as possible, papers published in either English or Chinese were collected from two databases, the Web of Science and the China National Knowledge Infrastructure (CNKI), the largest database of Chinese academic journals. Twenty-seven papers that included 120 data points were collected according to the following criteria: the measurement data must have been conducted under field conditions, $\mathrm{CH}_{4}$ and $\mathrm{N}_{2} \mathrm{O}$ fluxes must have been measured over an entire growth period of rice using the static chamber method, and both rice yield and GHG emissions had to be determined simultaneously. If some authors published their results on rice yield and GHG emissions in separate papers, those data were obtained from separate publications. In some studies, the same treatment was measured in more than 1 year, and then the mean value of measurements in different years was used as a single observation. Based on a survey of existing rice varieties in China, two groups of rice variables (japonica and indica rice varieties, subspecies in Asian cultivated rice and the most cultivated), GDAT and fertility management practices were assessed in this analysis. The detailed database is listed in Appendix S1. 


\subsection{Data analysis}

\subsubsection{Calculation of the GWP}

Two GWP indices (area-scaled and yield-scaled GWP) were calculated for each observation to evaluate the integrated impacts of rice varieties on GHG emissions and rice yields. Area-scaled GWP represented the overall GWP of $\mathrm{CH}_{4}$ and $\mathrm{N}_{2} \mathrm{O}$ emissions per unit rice field (ha) and was used to evaluate the impacts of rice varieties on emissions. Yield-scaled GWP represented the overall GWP per unit rice yield $(\mathrm{Mg})$, and was used to evaluate the comprehensive impacts of rice varieties on GHG emissions and rice yield. The 100-year radiative forcing potential coefficients relative to $\mathrm{CO}_{2}$ were 25 and 298 for $\mathrm{CH}_{4}$ and $\mathrm{N}_{2} \mathrm{O}$, respectively (IPCC, 2007).

\subsubsection{Impacts of rice varieties}

We used the methods of Linquist et al. (2012a) to evaluate the mean GHG emissions, area-scaled GWP, rice yield, and yield-scaled GWP for the two kinds of rice varieties. The equations used were as follows:

$$
\begin{aligned}
M & =\sum\left(Y_{i} \times W_{i}\right) / \sum W_{i} \\
W_{i} & =n \times f / o .
\end{aligned}
$$

Equation (1) was used to calculate the weighted mean values for two kinds of rice varieties, japonica and indica rice varieties. Here, $\mathrm{M}$ is the mean value of $\mathrm{CH}_{4}, \mathrm{~N}_{2} \mathrm{O}$, areascaled GWP, rice yield, or yield-scaled GWP for two kinds of rice varieties, respectively. $Y_{i}$ is the observation of $\mathrm{CH}_{4}$, $\mathrm{N}_{2} \mathrm{O}$, area-scaled GWP, rice yield or yield-scaled GWP at the $i$ th site, respectively. $W_{i}$ is the weight for the observations from the $i$ th site and was calculated using Eq. (2), where $n$ is the number of replicates in the field experiment and $f$ is the number of GHG measurements per month for the weight of GHG emissions and the GWP indices. To prevent studies with high sampling frequencies from being assigned extreme weights, a maximum value of $f=5$ was assigned when GHG fluxes were measured more than once a week. For rice yields, we set $f=1$ because it was measured once per growing season. $o$ is the total number of observations from the $i$ th site. This weighting approach assigned more weight to field measurements that were well replicated and more precise flux estimates, and adjusted the weights by the total number of observations from one site to avoid studies with many observations at one site from dominating the data set (Linquist et al., 2012a). In this assessment of rice varieties, we only selected experiments that included widespread rice varieties used by local farmers. Experiments with rare cropping practices that were only used by scientific tests, such as upland rice (Kreye et al., 2007), were excluded from this analysis.

\subsubsection{Impacts of GDAT}

GDAT was divided into seven time ranges, 70-80, 80-90, 90-100, 100-110, 110-120, 120-130, and > 130 days of GDAT. The impacts of GDAT were assessed using the same methods applied to assess the other impacts of rice varieties. In this study, we did not consider GHG emissions during the non-growing season when temperature is relatively low and rice paddies are drained, and thus $\mathrm{CH}_{4}$ and $\mathrm{N}_{2} \mathrm{O}$ emissions are relatively low.

\subsubsection{Impacts of fertility management practices}

Fertility management practices, such as $\mathrm{N}$ fertilization, were assessed in this study. Their impacts on GHG emissions, area-scaled GWP, rice yield, and yield-scaled GWP were evaluated using the response ratio ( $R$; Hedges et al., 1999). Only studies that included side-by-side comparisons were selected in the meta-analysis. Rates of $\mathrm{N}$ application were empirically divided into five levels $(50-100,100-150,150-200$, 200-250, and 250-300 $\mathrm{kg} \mathrm{N} \mathrm{ha}^{-1}$ season $^{-1}$ ). The $\mathrm{N}$ fertilizers in the selected studies were ammonium-based, such as urea, but ammonium sulfate was excluded because it is rarely used by rice farmers in China. The natural log of the response ratio $(\ln R)$ was calculated as the index of the effect size

$\ln R=\ln X t / X c$,

where $X t$ and $X c$ are measurements for the treatment and control, respectively. The controls were non-fertilized and were relative to $\mathrm{N}$ fertilization. The mean of the response ratio was calculated from the $\ln R$ values of individual studies by

$M=\exp \left[\sum \ln R_{(i)} \times W_{(i)} / \sum W_{(i)}\right]$.

In Eq. (4), $W_{(i)}$ is the weighting factor and is estimated by

$W_{(i)}=n \times f$,

where $n$ is the number of experimental replicates and $f$ is the number of GHG measurements per month for GHG emissions and GWP indices or measurements per growing season for rice yield. Because the response ratio was calculated as that of the treatment to the control at the same site in each study, the effect size mainly reflected the effect of the treatment on GHG emissions and was rarely affected by the site. Therefore, the weight of the response ratio was not adjusted by the number of observations at the $i$ th site, as in Eq. (2).

\subsubsection{Meta-analysis}

The meta-analysis was performed using MetaWin 2.1 (Rosenberg et al., 2000). A random-effect model was used to calculate the mean effect sizes based on the assumption that random variations in GHG emissions occurred between observations. The $95 \%$ confidence intervals (CIs) around the 
(a) $\mathrm{CH}_{4}\left(\mathrm{~kg} \mathrm{CO} 2\right.$ equiv. ha $\left.{ }^{-1}\right)$

(b) $\mathrm{N}_{2} \mathrm{O}\left(\mathrm{kg} \mathrm{CO}_{2}\right.$ equiv. ha $\left.{ }^{-1}\right)$

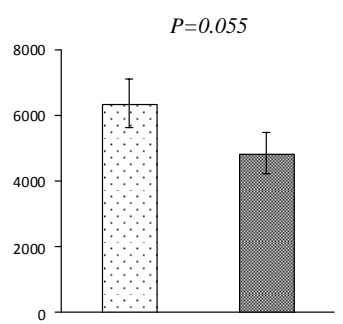

(c) Area-scaled GWP ( $\mathrm{kg} \mathrm{CO}_{2}$ equiv. ha ${ }^{-1}$ )

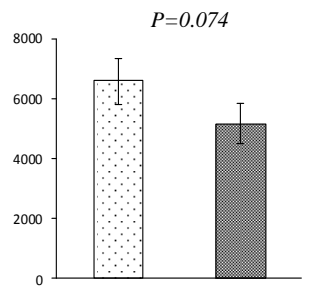

(e) Yield-scaled GWP $\left(\mathrm{kg} \mathrm{CO}_{2}\right.$ equiv. $\left.\mathrm{Mg}^{-1}\right)$

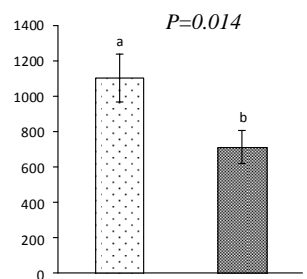

Figure 1. Impacts of cropping systems on $\mathrm{CH}_{4}$ and $\mathrm{N}_{2} \mathrm{O}$ emissions, area-scaled GWP, rice grain yield, and yield-scaled GWP during rice varieties types. The data in the bracket were the numbers of observation. All error bars represented $95 \%$ confidence intervals.

mean effect sizes were calculated by using bootstrapping with 4999 iterations (Rosenberg et al., 2000; Linquist et al., 2012a). Mean effect sizes were considered significantly different if their $95 \%$ CIs did not overlap.

\section{Results}

\subsection{Impacts of rice varieties}

Substantial differences were observed in the impacts of rice variety type on GHG emissions, rice yield, and GWP (Fig. 1). The $\mathrm{CH}_{4}$ and $\mathrm{N}_{2} \mathrm{O}$ emissions were 6355.81 and $266.75 \mathrm{~kg} \mathrm{CO}_{2}$ equiv. ha ${ }^{-1}$ for indica rice varieties, and 4845.02 and $294.96 \mathrm{~kg} \mathrm{CO}_{2}$ equiv. ha ${ }^{-1}$ for japonica rice varieties. The differences in $\mathrm{CH}_{4}$ emissions $(p=0.055)$ and $\mathrm{N}_{2} \mathrm{O}$ emissions $(p=0.289)$ between the two kinds of rice were not statistically significant (Fig. 1a, b). In terms of the area-scaled GWP values, indica rice varieties had greater values than japonica rice varieties (Fig. 1c). However, the trend (a) $\mathrm{CH}_{4}\left(\mathrm{~kg} \mathrm{CO}_{2}\right.$ equiv. ha $\left.{ }^{-1}\right)$

(b) $\mathrm{N}_{2} \mathrm{O}\left(\mathrm{kg} \mathrm{CO}_{2}\right.$ equiv. ha $\left.{ }^{-1}\right)$

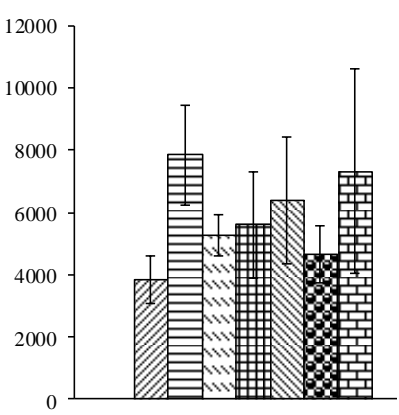

(c) Area-scaled GWP( $\mathrm{kg} \mathrm{CO}_{2}$ equiv. ha $\left.{ }^{-1}\right)$
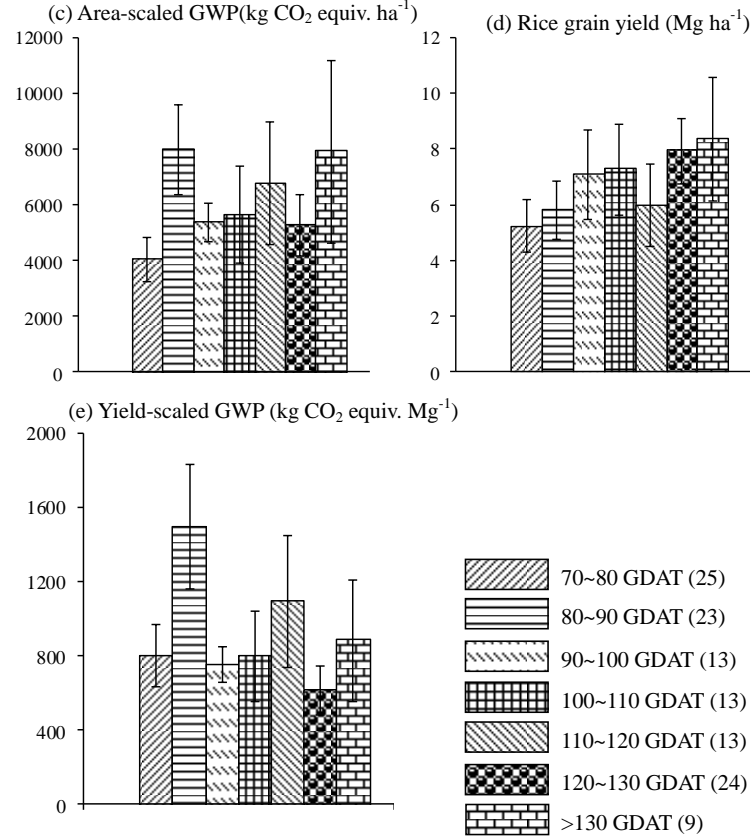

Figure 2. Impacts of cropping systems on $\mathrm{CH}_{4}$ and $\mathrm{N}_{2} \mathrm{O}$ emissions, area-scaled GWP, rice grain yield, and yield-scaled GWP during different growth duration after transplanting (GDAT). The data in the bracket were the numbers of observation. All error bars represented $95 \%$ confidence intervals.

in rice yield was opposite (Fig. 1d). As a result, a statistically significant ( $p=0.014)$ higher yield-scaled GWP occurred in indica rice varieties $\left(1101.72 \mathrm{~kg} \mathrm{CO}_{2}\right.$ equiv. $\left.\mathrm{Mg}^{-1}\right)$ compared to japonica rice varieties $\left(711.38 \mathrm{~kg} \mathrm{CO}_{2}\right.$ equiv. $\left.\mathrm{Mg}^{-1}\right)$ (Fig. 1e), indicating the japonica rice varieties released less GHGs with higher yields.

\subsection{Impact of the growth duration after transplanting (GDAT)}

The lowest and highest $\mathrm{CH}_{4}$ emissions among the different GDAT were $70-80$ days (3826.93 $\mathrm{kg} \mathrm{CO}_{2}$ equiv. ha ${ }^{-1}$ ) and 80-90 days (7833.12 $\mathrm{kg} \mathrm{CO}_{2}$ equiv. $\mathrm{ha}^{-1}$ ), respectively (Fig. 2a). $\mathrm{N}_{2} \mathrm{O}$ emissions were low, from 70 to 110 days. When GDAT was more than 110 days, $\mathrm{N}_{2} \mathrm{O}$ emissions tended to increase significantly (Fig. 2b). Consequently, 


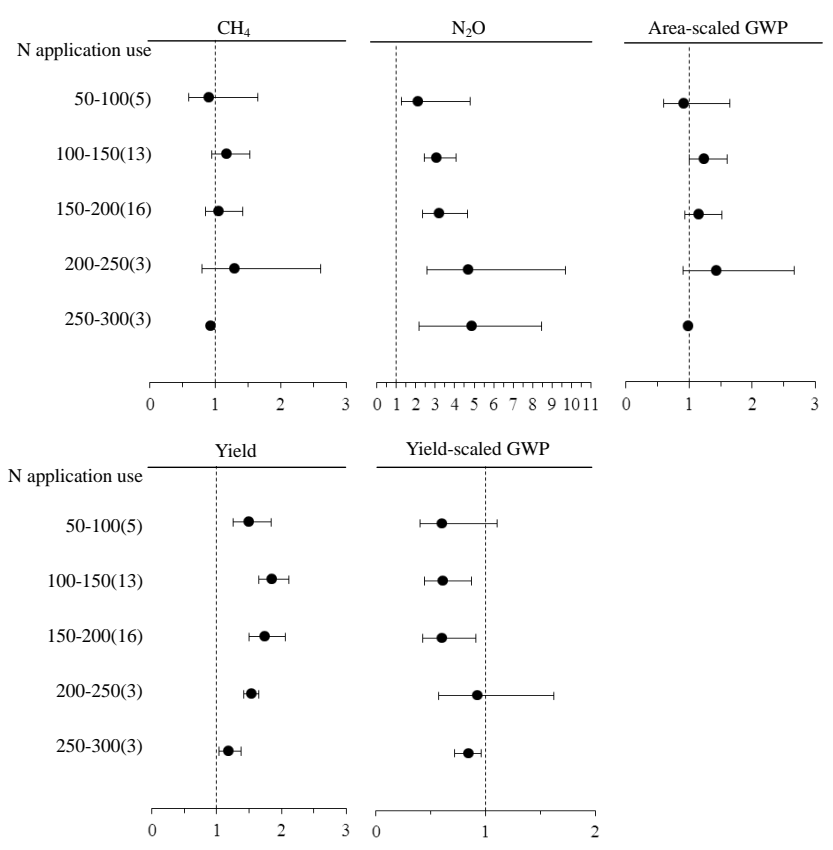

Figure 3. Effects of different $\mathrm{N}$ application rates on $\mathrm{CH}_{4}$ and $\mathrm{N}_{2} \mathrm{O}$ emissions, area-scaled GWP, rice yield, and yield-scaled GWP. The data were expressed as mean response ratios with $95 \%$ confidence intervals, and the numbers of observations included were indicated in parentheses.

area-scaled GWP values were similar, between 80 and $90\left(7981.74 \mathrm{~kg} \mathrm{CO}_{2}\right.$ equiv. $\left.\mathrm{ha}^{-1}\right)$ and $>130$ days of GDAT (7915.32 $\mathrm{kg} \mathrm{CO}_{2}$ equiv. ha ${ }^{-1}$; Fig. 2c). Rice yields tend to increase significantly with prolonged GDAT (Fig. 2d). Therefore, the highest yield-scaled GWP occurred at 80-90 days of GDAT (1495.56 $\mathrm{kg} \mathrm{CO}_{2}$ equiv. $\mathrm{Mg}^{-1}$ ), followed by 110 $120\left(1093.85 \mathrm{~kg} \mathrm{CO}_{2}\right.$ equiv. $\left.\mathrm{Mg}^{-1}\right)$ and $>130$ days of GDAT (881.32 $\mathrm{kg} \mathrm{CO}_{2}$ equiv. $\mathrm{Mg}^{-1}$; Fig. 2e). The lowest yieldscaled GWP occurred at 120-130 days of GDAT.

\subsection{Impact of $\mathbf{N}$ fertilization}

The response ratios for GHG emissions, area-scaled GWP, rice yield, and yield-scaled GWP with $\mathrm{N}$ fertilizer application as compared to non-fertilized controls are presented in Fig. 3. The response ratios for $\mathrm{CH}_{4}$ emissions were around 1 , indicating that $\mathrm{N}$ fertilization had no significant stimulating or mitigating effects on $\mathrm{CH}_{4}$ emissions. The response ratios for $\mathrm{N}_{2} \mathrm{O}$ were significantly greater than 1 and increased with the $\mathrm{N}$ application rate, indicating that significant stimulation of $\mathrm{N}_{2} \mathrm{O}$ emissions occurred with $\mathrm{N}$ fertilization. Consequently, the response ratios for area-scaled GWP values of $\mathrm{CH}_{4}$ and $\mathrm{N}_{2} \mathrm{O}$ emissions tended to be equal to or higher than 1, indicating slight stimulation of area-scaled GWP with $\mathrm{N}$ fertilization. The response ratios for rice yield were all significantly higher than 1 , and yield gains (18-86\%) were significantly higher than GWP variations ( $-7 \%$ to $43 \%)$ at the area scale with $\mathrm{N}$ application. As a result, the response ra- tios for yield-scaled GWP were all less than 1, indicating a reduction in yield-scaled GWP with $\mathrm{N}$ fertilization.

According to the response ratios for the yield-scaled GWP, the mitigating effects of $\mathrm{N}$ fertilization on the yieldscaled GWP were 7-41\% compared with non-fertilized controls. Among the five $\mathrm{N}$ application rates, the largest reduction, $41 \%$, occurred with an application rate of 150 $200 \mathrm{~kg} \mathrm{Nha}^{-1}$. When the application rate was higher than $200 \mathrm{~kg} \mathrm{Nha}^{-1}$, the mitigating effects of $\mathrm{N}$ application on GWP tended to decrease at the yield scale. Therefore, an application rate of $150-200 \mathrm{~kg} \mathrm{~N}^{-1}$ should be recommended to produce the least $\mathrm{CH}_{4}$ and $\mathrm{N}_{2} \mathrm{O}$ production at the same yield.

\section{Discussion}

\subsection{Differences in the effects of rice varieties on yield-scaled GWP}

Recently, increasing efforts have been directed toward assessing GHG emissions from crop production at the yield scale rather than the area scale (Pathak et al., 2010; Van Groenigen et al., 2010; Venterea et al., 2011; Linquist et al., 2012a). We found that the yield-scaled GWP provided more useful information in comparing rice varieties than area-scaled GWP (Fig. 1). The average yield-scaled GWP of japonica rice varieties $\left(711.4 \mathrm{~kg} \mathrm{CO}_{2}\right.$ equiv. $\left.\mathrm{Mg}^{-1}\right)$ was similar to the estimated value for global rice production ( $657 \mathrm{~kg} \mathrm{CO}_{2}$ equiv. $\mathrm{Mg}^{-1}$ ) published by Linquist et al. (2012a) and for a rice-upland cropping system (777.0 $\mathrm{kg} \mathrm{CO}_{2}$ equiv. $\mathrm{Mg}^{-1}$ ) reported by Feng et al. (2013). Our meta-analysis results are different from some single site results in that the yield-scaled GWP of indica rice varieties (1101.7 $\mathrm{kg} \mathrm{CO}_{2}$ equiv. $\mathrm{Mg}^{-1}$ ) was similar to values in India rice production ( $1146.3 \mathrm{~kg} \mathrm{CO}_{2}$ equiv. $\mathrm{Mg}^{-1}$ ) (Pathak et al., 2010), and different from a double-rice cropping system ( $1188.9 \mathrm{~kg} \mathrm{CO}_{2}$ equiv. $\mathrm{Mg}^{-1}$ ) described by Feng et al. (2013). These findings indicate a possibly varietal difference in gas transport capacity from soil to the atmosphere among cultivars, and open the possibility for breeding rice cultivars with low GHG emissions.

We found that $\mathrm{CH}_{4}$ emissions were significantly higher from indica rice fields than from japonica rice fields. Similar results were found in other studies (Ma et al. 2010). Because more than $80 \%$ of both $\mathrm{N}_{2} \mathrm{O}$ and $\mathrm{CH}_{4}$ were emitted through rice plants (Yu et al., 1997), significant differences could be found in the yield-scaled GWP between the rice varieties. Several factors can affect $\mathrm{CH}_{4}$ emissions among different rice varieties, for example, (1) aerenchyma tissues, (2) root biomass, and (3) transplanting style. Butterbach-Bahl et al. (1997) pointed out that observed differences in $\mathrm{CH}_{4}$ emissions in the field between the cultivars Lido and Roma can be explained by differences in gas transport capacity, which resulted from differences in the morphology of the aerenchyma 
systems, especially in the root-shoot transition zone. From an analysis of 16 indica rice varieties, Fu et al. (2007) reported that plant height, the area of vascular bundles, and the area of gas chambers in leaf sheaths are crucial factors influencing $\mathrm{CH}_{4}$ emissions through the plant aerenchyma system. Aulakh et al. (2000) clearly demonstrated that rice cultivars differ significantly in their $\mathrm{CH}_{4}$ transport capacity by examining 12 cultivars (10 inbred varieties and 2 hybrids). Similar results were found by Butterbach-Bahl et al. (1997) when testing two Italian rice (Oryza sativa var. japonica) cultivars (Lido and Roma) in the field. Aerenchyma tissues of plants can significantly stimulate $\mathrm{CH}_{4}$ emissions from rice fields (Butterbach-Bahl et al., 1997; Yan et al., 1997; Fu et al., 2007). Previous studies have indicated that the use of high-yielding cultivars with low $\mathrm{CH}_{4}$ transport capacities could provide an economically feasible, environmentally sound, and promising approach for mitigating $\mathrm{CH}_{4}$ emissions from rice fields (Butterbach-Bahl et al., 1997; Aulakh et al., 2000). On root biomass, Wang et al. (1999) indicated that differences in $\mathrm{CH}_{4}$ emission rates among rice cultivars were determined by differences in root biomass. Xu et al. (1999) stated that a positive correlation existed between $\mathrm{CH}_{4}$ emissions and root biomass, and similar results were observed by Wang et al. (1997). High exudation rates could be caused by higher root biomass but not by a higher activity of the root tissue (Lu et al., 1999). Deposits of organic root exudates, sloughed-off cells, and decaying root debris serve as the major carbon sources for $\mathrm{CH}_{4}$ production in rice fields (Lu et al., 2000a, b). Regarding the transplanting style, Ko and Kang (2000) found that transplanting 30-day-old seedlings, direct seeding on wet soil, and direct seeding on dry soil reduced $\mathrm{CH}_{4}$ emission by $5 \%, 13 \%$ and $37 \%$, respectively, when compared with transplanting 8-day-old seedlings. Pathak et al. (2013) concluded that direct seeding of rice (DSR) was a feasible alternative for significantly reducing $\mathrm{CH}_{4}$ emissions in addition to saving water and labor. Fu et al. (2008), however, reported that $\mathrm{CH}_{4}$ flux under DSR was significantly lower, but that the amount of $\mathrm{CH}_{4}$ emissions under DSR was significantly greater than under TPR based on the rice growth stage in paddy fields. One possible reason was that they did not measure the amount of $\mathrm{CH}_{4}$ emissions during the seedling stage under TPR conditions.

These differences in area-scaled and yield-scaled GWP demonstrate a potential for agronomic alterations to achieve higher yields with lower GHG emissions by changing rice varieties (indica vs. japonica rice varieties) in China. Areascaled and yield-scaled GWP could be reduced by $22 \%$ and $35 \%$, respectively (Fig. 1), if indica rice varieties were replaced by japonica rice varieties in the same paddy fields. Because most previous studies focused on investigating GHG emissions in either indica or japonica rice varieties, not enough published references were available for us to assess differences in GHG emissions between other rice varieties, such as upland rice. Additional field observations of GHG emissions should be conducted with more rice varieties to allow a comprehensive assessment of GHG emissions with different kinds of rice varieties.

\subsection{Differences in the effects of GDAT on yield-scaled GWP}

Growth duration from seed to seed in rice varieties varies with latitude and elevation. Consequently, we selected the GDAT (the period from transplanting to harvesting) in our study as a criterion to eliminate this difference. We found that the highest yield-scaled GWP occurred at 80-90 days of GDAT. All rice varieties in 70-90 days of GDAT belonged to early rice (e.g., Shang et al., 2011; Shi et al., 2011a, b; Fu et al., 2012), for which the yield-scaled GWP was $1148.20 \mathrm{~kg} \mathrm{CO}_{2}$ equiv. $\mathrm{Mg}^{-1}$. Feng et al. (2013) also reported that the yield-scaled GWP in early rice in a doublerice cropping system was $1125 \mathrm{~kg} \mathrm{CO}_{2}$ equiv. $\mathrm{Mg}^{-1}$. Our results further demonstrated significant differences in the yield-scaled GWP between 70-80 and 80-90 days of GDAT. Yield-scaled GWP in 80-90 days of GDAT was $87 \%$ higher than in 70-80 days of GDAT. In addition, Feng et al. (2013) reported that yield-scaled GWP in late rice in a double-rice cropping system was $1298.08 \mathrm{~kg} \mathrm{CO}_{2}$ equiv. $\mathrm{Mg}^{-1}$, which was $73 \%$ higher than in $90-100$ days of GDAT. Yield-scaled GWP (777.00 $\mathrm{kg} \mathrm{CO}_{2}$ equiv. $\mathrm{Mg}^{-1}$ ) in a rice-upland cropping system reported by Feng et al. (2013) was similar to that of $>120$ days of GDAT (747.50 $\mathrm{kg} \mathrm{CO}_{2}$ equiv. $\mathrm{Mg}^{-1}$ ), but it was significantly lower than the value in 100-120 days of GDAT $\left(944.10 \mathrm{~kg} \mathrm{CO}_{2}\right.$ equiv. $\mathrm{Mg}^{-1}$ ). More details were found in studies on the yield-scaled GWP in >100 days of GDAT. Yield-scaled GWP values in 100-110 and > 120 days of GDAT were higher than in 110-120 and > 130 days of GDAT, respectively.

As with rice varieties, differences in $\mathrm{CH}_{4}$ emissions were also the main contributors to significant differences in the yield-scaled GWP among GDAT categories. Several factors can affect $\mathrm{CH}_{4}$ emissions among GDAT categories, for example, rice variety and soil temperature. First, large differences exist in rice varieties among GDAT categories. The main varieties in the $>120$ days of GDAT category were almost all japonica rice; both japonica and indica rice were found in 100-120 days of GDAT, while indica rice was almost exclusive in the 70-100 days of GDAT category. Previous studies have reported that $\mathrm{CH}_{4}$ emissions are significantly higher from indica rice fields than from japonica rice fields (Liou et al., 2003; Ma et al., 2010). Similar results were found in this study. Second, the average soil temperature during the rice growing season was about $15^{\circ} \mathrm{C}$ for a single-rice cropping system (Yue et al., 2005), $26^{\circ} \mathrm{C}$ for a rice-upland crop rotation cropping system (Cai et al., 2003), and $25^{\circ} \mathrm{C}$ for a double-rice cropping system (Yang et al., 2010). Increases in soil temperature can significantly stimulate $\mathrm{CH}_{4}$ emissions from rice fields (Parashar et al., 1993).

Because most previous studies focused on examining GHG emissions during GDAT, few published references 
were available to assess the impacts of rice varieties on GHG emissions during the seedling stage. Ma et al. (2012) indicated that $\mathrm{CH}_{4}$ emissions during the seedling stage must be considered to calculate an accurate national $\mathrm{CH}_{4}$ budget for rice agriculture. Additional field observations of GHG emissions in rice varieties should be conducted from seeds to seeds to complete life cycle assessments of GHG emissions in various rice varieties.

\subsection{Differences in the effects of $\mathrm{N}$ fertilization on yield-scaled GWP}

$\mathrm{N}$ fertilization is one of the major fertilizer management practices for increasing rice yield and sustaining soil fertility, but it also significantly stimulates $\mathrm{N}_{2} \mathrm{O}$ emissions (Kumar et al., 2000; Zou et al., 2005). Although no significant stimulation or reduction in $\mathrm{CH}_{4}$ emissions were observed (Cai et al., 2007; Linquist et al., 2012b), the area-scaled GWP of $\mathrm{CH}_{4}$ and $\mathrm{N}_{2} \mathrm{O}$ emissions was stimulated by $\mathrm{N}$ fertilization. However, our meta-analysis showed that $\mathrm{N}$ fertilization increased rice yield more than the GWP of $\mathrm{CH}_{4}$ and $\mathrm{N}_{2} \mathrm{O}$ emissions, which resulted in a large reduction in the yieldscaled GWP. Moreover, the greatest reduction, $41 \%$ compared to non-fertilized controls, occurred with an application rate of $150-200 \mathrm{~kg} \mathrm{Nha}^{-1}$. This rate was close to the recommended fertilization rate for high rice yield in China (Ju et al., 2004). Similar results were found in the study by Feng et al. (2013), with a $37 \%$ emission reduction relative to unfertilized controls occurring with an application rate of $150-200 \mathrm{~kg} \mathrm{Nha}^{-1}$. Overuse of $\mathrm{N}$ will not only reduce rice yield gain but also stimulate $\mathrm{N}_{2} \mathrm{O}$ emissions, resulting in higher GHG emissions at the yield scale. Thus, a balance between rice yield increase and GHG emission reductions can be achieved by adjusting the $\mathrm{N}$ application rate.

\subsection{Cultivar choice and pairs in major Chinese rice cropping systems}

The major Chinese rice cropping systems were divided into three groups: annual single-rice cropping $(17.0 \%$ of the total rice production), annual rice-upland crop rotation (ricewheat or rice-rape seed rotation; $49.0 \%$ of the total rice production), and annual double-rice cropping (34.0\% of the total rice production; National Bureau of Statistics of China, 2011). Feng et al. (2013) indicated that the yield-scaled GWP in double-rice cropping systems, rice-upland crop rotation systems, and single rice cropping systems were 1188.9, 777.0 , and $346.7 \mathrm{~kg} \mathrm{CO}_{2}$ equiv. $\mathrm{Mg}^{-1}$, respectively. Linquist et al. (2012a) reported that the yield-scaled GWP of global rice production was $657 \mathrm{~kg} \mathrm{CO}_{2}$ equiv. $\mathrm{Mg}^{-1}$. Proper cultivar choice and pairs (CCAP) is of vital importance in rice cropping systems if GHG emissions are to be further reduced, especially in double-rice cropping systems. Yield-scaled GWP could be reduced by $35 \%$ if japonica rice varieties in major Chinese rice cropping systems replace indica rice vari- eties in the same paddy fields. Within the climate limitation, if 70-80 days of GDAT early rice in double-rice cropping systems replace 80-90 days of GDAT rice, the yield-scaled GWP could be reduced by $47 \%$. If 100-110 days of GDAT varieties in rice-upland cropping systems replace 110-120 days of GDAT varieties, the yield-scaled GWP could be lowered by $38 \%$. Finally, if $120-130$ days of GDAT varieties in single-rice cropping systems replace $>130$ days of GDAT varieties, the yield-scaled GWP could be reduced by $30 \%$.

\section{Conclusions}

To achieve a trade-off between increasing rice yield and reducing GHG emissions during cultivar choice and pairs (CCAP) and rice production policy selection, we conducted a meta-analysis on GHG emissions at the yield scale based on field observations in China. This analysis indicated that the highest yield-scaled GHG occurred in indica rice varieties compared to japonica rice varieties. Moreover, a lower yieldscaled GHG occurred in 120-130 days of GDAT, followed by $90-100,100-110$, and finally $70-80$ days of GDAT. For example, better CCAP in the double-rice region in Hunan Province would use 70-80 days of GDAT (early rice) and 90-100 days of GDAT (late rice) varieties. In the Huaihai River plain and hilly areas, better CCAP in the rice-upland cropping system would use 100-110 days of GDAT varieties. In the Sanjiang Plain, better CCAP in the single rice system would use 120-130 days of GDAT rice.

$\mathrm{N}$ fertilization can reduce yield-scaled GHG emissions from paddy fields, with the optimal fertilization rate falling in the range of $150-200 \mathrm{~kg} \mathrm{~N} \mathrm{ha}^{-1}$. Though $\mathrm{N}$ fertilization promoted $\mathrm{N}_{2} \mathrm{O}$ emissions, it increased rice yield more than $\mathrm{CH}_{4}$ and $\mathrm{N}_{2} \mathrm{O}$ emissions. A balance between rice yield increase and GHG emission reductions can be achieved by adjusting the $\mathrm{N}$ application rate.

Due to limitations in the existing field observations, only direct GHG emissions in indica or japonica rice varieties, or GDAT in the same rice varieties, were assessed in this study. In the future, more efforts should be spent on field observations of direct GHG emissions from multiple rice varieties and throughout the entire growing period, from seeds to seeds, e.g., on comparing indica and japonica rice varieties during the seedling stage. Life cycle assessments of GHG emissions from various rice varieties at the yield scale are critical and urgently needed for the development of winwin policies for rice production to achieve higher yields with lower emissions.

The Supplement related to this article is available online at doi:10.5194/bg-11-3685-2014-supplement. 
Acknowledgements. We thank W. J. Zhang and J. F. Feng, Nanjing Agricultural University, and H. Xu, Hunan Agricultural University, for advice on the statistical analysis and for valuable feedback on earlier versions of this manuscript. This research was part of the National Programs for High-Yielding Rice Science and Technology (Grant no. 2013BAD07B11) and the Project for "12th 5-year plan" Agro-scientific Research in the Public Interest (Grant No. 201203081).

Edited by: X. Wang

\section{References}

Aulakh, M. S., Bodenbender, J., Wassmann, R., and Rennenberg, H.: Methane transport capacity of rice plants, II. variations among different rice cultivars and relationship with morphological characteristics, Nutr. Cycl. Agroeco., 58, 367-375, 2000.

Baruah, K. K., Gogoi. B., and Gogoi, P.: Plant physiological and soil characteristics associated with methane and nitrous oxide emission from rice paddy, Physiol. Mol. Biol. Plants., 16, 79-91, 2010.

Butterbach-Bahl, K., Papen, H., and Rennenberg, H.: Impact of gas transport through rice cultivars on methane emission from rice paddy field, Plant, Cell Environ., 20, 1175-1183, 1997.

Cai, Z., Tsuruta, H., Gao, M., Xu, H., and Wei, C.: Options for mitigating methane emission from a permanently flooded rice field, Glob. Change Biol., 9, 37-45, 2003.

Cai, Z., Shan, Y., and Xu, H.: Effects of nitrogen fertilization on $\mathrm{CH}_{4}$ emissions from rice fields, Soil Sci. Plant Nutr., 53, 353361, 2007.

FAOSTAT: available at: http://faostat.fao.org., 2011.

Feng, J. F., Chen, C. Q., Zhang, Y., Song, Z. W., Deng, A. X., Zheng, C. Y., and Zhang, W. J.: Impacts of cropping practices on yield-scaled greenhouse gas emissions from rice fields in China: a meta-analysis, Agr. Ecosyst. Environ., 164, 220-228, 2013.

$\mathrm{Fu}, \mathrm{Z}$. Q. and Huang, H.: Impact of rice cultivation patterns on methane emission from paddy field, J. Agro-Environ. Sci., 27, 2513-2517, 2008.

Fu, Z. Q., Huang, H., He, B. L., Xie, W., and Liao, X. L.: Correlation between rice plant aerenchyma system and methane emission from paddy field, Acta Agron. Sincia, 33, 1458-1467, 2007.

Fu, Z. Q., Huang, H., Xie, W., and He, B. L.: Effects of highyielding rice cultivar and cultivation pattern on methane emission from paddy field, Chinese J. App. Eco., 20, 3003-3008, 2009.

Fu, Z. Q., Zhu, H. W., Chen, C., and Huang, H.: Characterization of $\mathrm{CH}_{4}, \mathrm{~N}_{2} \mathrm{O}$ emission and selection of rice cultivars in double cropping rice fields, Environ. Sci., 33, 2475-2481, 2012.

Hedges, L. V., Gurevitch, J., and Curtis, P.S.: The meta-analysis of response ratios in experimental ecology, Ecology, 80, 11501156, 1999.

IPCC-Intergovernmental Panel on Climate Change: The Supplementary Report to IPCC Scientific Assessment, edited by: Houghton, J. T., Callander, B. A., and Varney, S. K., Cambridge University Press, Cambridge, 1992.

IPCC-Intergovernmental Panel on Climate Change: Climate Change 2007: The Physical Science Basis, Cambridge University Press, Cambridge, UK and New York, NY, USA, 2007.
Ju, X., Liu, X., Zhang, F., and Roelcke, M.: Nitrogen fertilization, soil nitrate accumulation, and policy recommendations in several agricultural regions of China, Ambio, 33, 300-305, 2004.

Khush, G. S.: Breaking the yield frontier of rice, Geo J., 35, 329332, 1995.

Ko, J. Y. and Kang, H. W.: The effects of cultural practices on methane emission from rice fields, Nutr. Cycl. Agroeco., 58, 311-314, 2000.

Kreye, C., Dittert, K., Zheng, X. H., Zhang, X., Lin, S., Tao, H. B., and Sattelmacher, B.: Fluxes of methane and nitrous oxide in water-saving rice production in north China, Nutr. Cycl. Agroeco., 77, 293-304, 2007.

Kumar, U., Jain, M. C., Pathak, H., Kumar, S., and Majumdar, D.: Nitrous oxide emission from different fertilizers and its mitigation by nitrification inhibitors in irrigated rice, Biol. Fert. Soils, 32, 474-478, 2000.

Lindau, C., Bollich, P., Delaune, R., Patrick, W., and Law, V.: Effect of urea fertilizer and environmental factors on $\mathrm{CH}_{4}$ emissions from a Louisiana, USA rice field, Plant Soil, 136, 195-203, 1991.

Linquist, B., Groenigen, K. J., Adviento-Borbe, M. A., Pittelkow, C., and Kessel, C.: An agronomic assessment of greenhouse gas emissions from major cereal crops, Glob. Change Biol., 18, 194-209, 2012a.

Linquist, B., Adviento-Borbe, M. A., Pittelkow, C. M., van Kessel, C., van and Groenigen, K. J.: Fertilizer management practices and greenhouse gas emissions from rice systems: a quantitative review and analysis, Field Crop. Res., 135, 10-21, $2012 b$.

Liou, R. M., Huang, S. N., Lin, C. W., and Chen, S. H.: Methane emission from fields with three various rice straw treatments in Taiwan paddy soils pesticides, J. Environ. Sci. Heal. B, 38, 511527, 2003.

Lu, Y., Wassmann, R., Neue, H. U., and Huang, C.: Impact of phosphorus supply on root exudation, aerenchyma formation and methane emission of rice plants, Biogeochemistry, 47, 203-218, 1999.

Lu, Y. H., Wassmann, R., Neue, H. U., and Huang, C. Y.: Dissolved organic carbon and methane emissions from a rice paddy fertilized with ammonium and nitrate, J. Environ. Qual., 6, 17331740, 2000a.

Lu, Y. H., Wassmann, R., Neue, H. U., and Huang, C. Y.: Dynamics of dissolved organic carbon and methane emissions in a flooded rice soil, Soil Sci. Soc. Am. J., 6, 2011-2017, 2000b.

Ma, K. Qiu, Q., and Lu, Y.: Microbial mechanism for rice variety control on methane emission from rice field soil, Glob. Change Biol., 16, 3085-3095, 2010.

National Bureau of Statistics of China: China Statistical Yearbook, China Statistical Publisher, Beijing, 2011.

Parashar, D. C., Gupta, P. K., Rai, J., Sharma, R. C., and Singh, N.: Effect of soil temperature on methane emission from paddy fields, Chemosphere, 26, 247-250, 1993.

Pathak, H., Jain, N., Bhatia, A., Patel, J., and Aggarwal, P. K.: Carbon footprints of Indian food items, Agri., Eco. Environ., 139, 66-73, 2010.

Pathak, H., Sankhyan, S., Dubey, D. S., Bhatia, A., and Jain, N.: Dry direct-seeding of rice for mitigating greenhouse gas emission: field experimentation and simulation, Paddy Water Environ., 11, 593-601, 2013. 
Peng, S., Tang, Q., and Zou, Y.: Current status and challenges of rice production in China, Plant Prod. Sci., 12, 3-8, 2009.

Rosenberg, M. S., Adams, D. C., and Gurevitch, J.: Meta WinStatistical Software for Meta-Analysis, Sinauer Associates Inc., Sunderland, 2000.

Shang, Q., Yang, X. X., Gao, C. M., Wu, P. P., Liu, J. J., Xu, Y. C., Shen, Q. R., Zou, J. W., and Guo, S. W.: Net annual global warming potential and greenhouse gas intensity in Chinese double rice-cropping systems: a 3 year field measurement in long-term fertilizer experiments, Glob. Change Biol., 17, 2196-2210, 2011.

Shi, S. W., Li, Y. E., Wan, Y. F., Qing, X. B., and Gao, Q. Z.: Observation for $\mathrm{CH}_{4}$ and $\mathrm{N}_{2} \mathrm{O}$ emissions under different rates of nitrogen and phosphate fertilization in double rice fields, Environm. Sci., 32, 1989-1907, 2011a.

Shi, S. W., Li, Y. E., Li, M. D., Wan, Y. F., Gao, Q. Z., Hua, P., and Qing, $\mathrm{X}$. B.: Annual $\mathrm{CH}_{4}$ and $\mathrm{N}_{2} \mathrm{O}$ emissions from double rice cropping systems under various fertilizer regimes in Hunan Province, China, Chinese J. Atmos. Sci., 35, 707-720, 2011 b.

Singh, J. S., Singh, S., Raghubanshi, A. S., Singh, S., and Kashyap, A. K.: Methane flux from rice/wheat agroecosystem as affected by crop phenology, fertilization and water level, Plant Soil, 183, 323-327, 1996.

Smith, P., Martino, D., Cai, Z.: Agriculture, in: Climate Change 2007: Mitigation. Contribution of Working Group III to the Fourth Assessment Report of the Intergovernmental Panel on Climate Change, edited by: Metz, B., Davidson, O. R., Bosch, P. R., Dave, R., and Meyer, L. A., Cambridge University Press, Cambridge, UK and New York, NY, USA, 497-540, 2007.

van Beek, C. L., Meerburg, B. G., Schils, R. L. M., Verhagen, J., and Kuikman, P. J.: Feeding the world's increasing population while limiting climate change impacts: linking $\mathrm{N}_{2} \mathrm{O}$ and $\mathrm{CH}_{4}$ emissions from agriculture to population growth, Environ. Sci. Policy, 13, 89-96, 2010.

van Groenigen, J. W., Velthof, G. L., Oenema, O., Van Groenigen, K. J., Van and Kessel, C.: Towards an agronomic assessment of $\mathrm{N}_{2} \mathrm{O}$ emissions: a case study for arable crops, Eur. J. Soil Sci., 61, 903-913, 2010.

van Groenigen, K. J., van Kessel, C., and Hungate, B. A.: Increased greenhouse-gas intensity of rice production under future atmospheric conditions, Nature Climate Change, 3, 288-291, 2013.

Venterea, R. T., Bijesh, M., and Dolan, M. S.: Fertilizer source and tillage effects on yield-scaled nitrous oxide emissions in a corn cropping system, J. Environ. Qual., 40, 1521-1531, 2011.

Wang, B., Neue, H. U., and Samonte, H. P.: Effect of cultivar difference on methane emission, Agric. Ecosyst. Environ., 62, 31-40, 1997.

Wang, Q. A., Lu, C. M., and Zhang, Q. D.: Middy photoinhibition of two newly developed super rice hybrid, Photosynthetica, 43, 277-281, 2005.
Wang, Z. P., Crozier, C. R., Kludze, H. K., and Patrick Jr., W. H.: Soil characteristics affecting methane production and emission in flooded rice fields, in: Climate Change and Rice, edited by: Peng, S., Ingram, K. T., Neue, H. U., and Ziska, L. H., Springer, Berlin Heidelberg, New York, 80-90, 1995.

Wang, Z. Y., Xu, Y. C., Li, Z., Wang, B. J., Guo, Y. X., Ding, Y. P., and Wang, Z. Z.: Effect of rice cultivars on methane emissions from rice field, Acta Agron. Sincia, 25, 441-446, 1999.

Xie, B., Zheng, X., Zhou, Z., Gu, J., Zhu, B., Chen, X., Shi, Y., Wang, Y., Zhao, Z., Liu, C., Yao, Z., and Zhu, J.: Effects of nitrogen fertilizer on $\mathrm{CH}_{4}$ emission from rice fields: multi-site field observations, Plant Soil, 326, 393-401, 2010.

Xu, Y. C., Wang, Z. Y., Li, Z., and Wang, B. J.: Effect of rice cultivars on methame emission from Beijing rice field, Plant Nutr. Fert. Sci., 5, 93-96, 1999 (in Chinese).

Yan, X., Akiyama, H., Yagi, K., and Akimoto, H.: Global estimations of the inventory and mitigation potential of methane emissions from rice cultivation conducted using the 2006 Intergovernmental Panel on Climate Change Guidelines, Global Biogeochem. Cy., 23, GB2002, doi:10.1029/2008GB003299, 2009.

Yang, X., Shang, Q., Wu, P., Liu, J., Shen, Q., Guo, S., and Xiong, Z.: Methane emissions from double rice agriculture under long-term fertilizing systems in Hunan, China, Agric. Ecosyst. Environ., 37, 308-316, 2010.

Yoshida, S.: Physiological consequences of altering plant type and maturity, in: Proceedings of the International Rice Research Conference, International Rice Research Institute, Los Bafios, Philippines, April, 1976.

Yu, K. W., Wang, Z. P., and Chen, G. X.: Nitrous oxide and methane transport through rice plants, Biol. Fert. Soils, 24, 341-343, 1997.

Yu, Y. Q., Huang, Y., Zhang, W.: Changes in rice yields in China since 1980 associated with cultivar improvement, climate and crop management, Field Crops Res., 136, 65-75, 2012.

Yue, J., Shi, Y., Liang, W., Wu, J., Wang, C. R., and Huang, G. H.: Methane and nitrous oxide emissions from rice field and related microorganism in black soil, northeastern China, Nutr. Cycl. Agroecosyst., 73, 293-301, 2005.

Zhang, W., Yu, Y., Huang, Y., Li, T., and Wang, P.: Modeling methane emissions from irrigated rice cultivation in China from 1960 to 2050, Glob. Change Biol., 17, 3511-3523, 2011.

Zou, J., Huang, Y., Jiang, J., Zheng, X., and Sass, R. L.: A 3 year field measurement of methane and nitrous oxide emissions from rice paddies in China: effects of water regime, crop residue, and fertilizer application, Global Biogeochem. Cy., 19, GB2021, doi:10.1029/2004GB002401, 2005.

Zou, J., Huang, Y., Zheng, X., and Wang, Y.: Quantifying direct $\mathrm{N}_{2} \mathrm{O}$ emissions in paddy fields during rice growing season in mainland China: dependence on water regime, Atmos. Environ., 41, 8030-8042, 2007. 